\title{
CONSIDERAÇÕES TEÓRICAS SOBRE IDENTIDADE DE LUGAR À LUZ DA ABORDAGEM HISTÓRICO-CULTURAL
}

\author{
Theoretical discussions about place-identity by historical-cultural approach
}

\author{
Alexandre Quintela Ponte ${ }^{[a]}$, Zulmira Áurea Cruz Bomfim ${ }^{[\mathrm{b}]}$, Jesus Garcia Pascual ${ }^{[\mathrm{c}]}$ \\ [a] Mestrando em Psicologia, Universidade Federal do Ceará (UFC), membro do LOCUS, Fortaleza,CE - Brasil, e-mail: \\ alquintela@hotmail.com \\ [b] Professora Doutora do Programa de Pós-Graduação em Psicologia da Universidade Federal do Ceará (UFC), coordenadora do \\ Laboratório de Pesquisa em Psicologia Ambiental, LOCUS, Fortaleza, CE - Brasil. \\ [c] Professor Doutor do Programa de Pós-Graduação em Psicologia da Universidade Federal do Ceará (UFC), Fortaleza, CE - Brasil.
}

\begin{abstract}
Resumo
Este artigo traz como principal foco de discussão o conceito de identidade de lugar. A proposta é fazer, inicialmente, uma contextualização do tema a partir das categorias espaço, lugar e não-lugar. Esta discussão inicial visa compreender essas categorias como construções semióticas e ideológicas, as quais se moldam a partir das interações humanas com o ambiente para além da simples ocupação física. Em seguida, apresentaremos a metodologia histórico-cultural de base materialista histórico-dialética, que possibilitará compreender a argumentação final do artigo; nesta etapa, o método será abordado historicamente com o objetivo de apontar as bases fundamentais à sustentação da visão de homem adotada por este estudo. Finalmente, discorreremos criticamente sobre identidade de lugar. Para esta tarefa, elegemos como principal centro de revisão teórica a concepção defendida por Proshansky, Fabian e Kaminoff. Identificamos que a linha de argumentação epistemológica desses autores segue uma vertente marcada pelo pragmatismo de Dewey e o interacionismo simbólico de George Mead. Assim, pensamos que pesquisar a relação de identificação das pessoas com os ambientes, tendo como método a abordagem histórico-cultural, exige definir esta categoria não pelo modelo de Proshansky et al., mas centrado epistemologicamente no próprio método histórico-cultural sob o risco de incongruência teórica. Portanto, defendemos uma concepção de identidade de lugar amalgamada à teoria da afetividade proposta por Bader Sawaia, onde afeto está ontologicamente ligado às dimensões ética e política. Consequentemente, identidade de lugar é pensada não apenas em termos de identificação com o ambiente, mas como possibilidade de vinculação afetiva e transformadora da realidade psicossocial.
\end{abstract}

Palavras-chave: Identidade de lugar. Metodologia. Afetividade. 


\begin{abstract}
This article brings as main focus of discussion the concept of place-identity. The proposal is, initially, to contextualize the concept from the categories space, place and non-place. This initial discussion aims to understand these categories as semiotic and ideological constructions, which are shaped from the human interactions with the environment beyond the mere physical occupation. Next, we will present the historical-cultural methodology of historical-dialectic materialist base, which will enable the comprehension of the article's final argumentation. In this stage, the method will be historically approached with the purpose of pointing the fundamental bases to support the vision of man adopted by this study. Finally, we will critically discuss about place-identity. For this task, we elect ${ }_{L}$ as main focus of theoretical revision, the notion defended by Proshansky, Fabian and Kaminoff. We identify that the line of epistemological argumentation of these authors follows a path marked by Dewey's pragmatism and George Mead's symbolic interactionism. Therefore, we think that investigating the identification of the people with the environments taking the historicalcultural approach as method demands defining this category not for Proshansky et al.'s model, but epistemologically centered in the cultural-historical method itself, at the risk of theoretical incongruence. This way, we defend a conception of place-identity combined to Bader Sawaya's theory of affection, where the ethical and political dimension is ontologically connected with the affect. As a result, place-identity is thought not only in terms of identification with the environment, but as possibility of affectionate bond to transform psychosocial reality.
\end{abstract}

Keywords: Place identity. Methodology. Affection.

\section{INTRODUÇÃO}

Uma característica interessante da relação entre as pessoas e os lugares é justamente a construção de significados e sentidos que possibilitam uma transformação de espaços em lugares, como já afirmou Yi-Fu Tuan (1983). A relação pessoal de experienciar os espaços - os quais remetem à ideia de amplidão, movimento e liberdade - e os lugares - os quais se relacionam com a ideia de objeto, segurança, estabilidade e proximidade constituem uma base imprescindível do processo de apropriação e significação dos lugares.

Para Tuan (1983), vivemos nos lugares, mas desejamos os espaços. Embora se possa experienciar nos lugares sentimentos que se vinculem à ideia de segurança, estabilidade, lar e outros. Há também, segundo o autor, um movimento pessoal que busca o desconhecido e o incerto na sua articulação com os espaços. O que exige do investigador uma postura que rejeite tomar as pessoas como seres passivos e sem capacidade de se implicar ativamente num processo de apropriação e significação dos lugares.

Tal processo de apropriação e significação dos lugares é crucial no entendimento do mecanismo de construção de uma identidade de lugar. Enric Pol e Sergi Valera (1999) discutem em seu artigo "Symbolisme de l'espace public et identitée sociale" que para um espaço se tornar um lugar simbólico deve passar por um processo de apropriação e significação. Para os autores, há dois tipos de processos de apropriação do espaço: um $a$ priori e outro a posteriori.

Por “apropriação a prior", Pol e Valera (1999) relatam as ações majoritariamente governamentais que visam promover ou propor a criação ou transformação de um entorno, a partir de uma direção ou intencionalidade determinada. Tal ação pretende estabelecer um espaço simbólico com uma significação predefinida que, por sua vez, pode ou não ser integrado pela população e se tornar um elemento simbólico compartilhado. Em consequência, os mesmos autores definem "apropriação a posterior" como referente aos espaços que foram ao longo do tempo e do uso se caracterizando como referenciais nodais no cotidiano de uma coletividade. Isto é, espaços que a partir da interação se tornaram lugares comuns e carregados de significados. O que implica pensar os espaços planejados como passíveis de significações completamente diferentes das que foram planejadas. 
Durante a Idade Média, notadamente no período de organização feudal da sociedade europeia, as pessoas geralmente permaneciam habitando um mesmo lugar por toda a vida, de acordo com Fourez (1995). O que implicava na construção de uma identidade com o lugar onde os elementos de referência do ambiente adquiriam propriedade quase "imutável" e que, em certa medida, favorecia a construção de relações sociais bem definidas quanto à manutenção e à reprodução de uma determinada forma de funcionamento social, político, econômico e religioso. Em comparação, dados do Censo Demográfico Brasileiro (IBGE, 2003) revelam que há um crescente número de deslocamentos no país. Por exemplo, do Censo de 1991 ao Censo de 2000 houve um aumento de 21\%, em todo o Brasil, no número de pessoas residindo em lugares diferentes dos de nascimento.

Esta constatação indica a existência na contemporaneidade de uma nova organização e significação dos lugares pelas pessoas. Nesta, os referenciais estáveis que outrora garantiam a orientação e definição clara das relações entre as pessoas e os lugares perdem sua constância, criando-se, assim, a necessidade de pensar tais relações não como estruturas fixas, mas em constante processo de negociação intersubjetiva e, também, como construção imagética destinada ao consumo mercadológico.

Encontramos ressonância deste posicionamento no trabalho de Marc Augé (2007, p. 73) que identificou a 'supermodernidade' como produtora de não-lugares. Segundo o autor, "o lugar se completa pela fala, a troca alusiva de algumas senhas, na convivência e na intimidade cúmplice dos locutores". O lugar possui um tripé basilar: ele é identitário, relacional e histórico. Assim, os não-lugares estariam na ordem dos espaços de passagens, nos hiatos espaciais que são preenchidos com signos previamente determinados e controlados. O não-lugar é diferente do espaço, pois este possui a característica de lugar praticado, lugar em movimento. Há, portanto, uma circunscrição que garante a este espaço caracteres identitários, relacionais e históricos. Noutra via, os não-lugares são:

[...] constituídos em relação a certos fins (transporte, trânsito, comércio, lazer) e a relação que os indivíduos mantêm com esses espaços. [...] os não-lugares medeiam todo um conjunto de relações consigo e com os outros que só dizem respeito indiretamente a seus fins: assim como os lugares antropológicos criam um social orgânico, os não-lugares criam tensão solitária (Augé, 2007, p. 87).

Consequentemente, a relação de produção deidentidades a partir do posicionamento de Augé (2007) orienta-se da seguinte forma: os não-lugares, por serem estruturas planejadas $a$ priorisegundo regras "contratuais de uso" imporiam a seus usuários uma identidade provisória, disponível apenas à circunscrição do não-lugar. Uma identidade a ser consumida solitariamente, pois "o espaço do não-lugar não cria nem identidade singular nem relação, mas sim solidão e similitude" (Augé, 2007, p. 95).

Constitui problema bastante interessante pensar a categoria identidade de lugar a partir destas considerações sobre espaço, lugar e nãolugar. Primeiro porque se coloca a tarefa de articular uma proposta de identidade que escapa aos conceitos fechados e que se abre a uma gama complexa de configurações. Pois os limites entre os conceitos basilares daquilo que se pretende construir como sendo identidade de lugar estão em constante interação e negociação. Afinal, dizer do espaço, do lugar e dos não-lugares de maneira clara e objetiva na construção da identidade não será tão simples, uma vez que essas relações produzem diferenciadas formas de compreensão da categoria que se põe aqui em estudo.

Finalmente, porque tal empreitada também cobrará do próprio conceito de identidade um posicionamento que possa dar entendimento destas relações discutidas no parágrafo anterior. Não se trata apenas de impor uma delimitação do real a partir de um conceito científico. Como foi demonstrada, a identidade de lugar se diferencia e se molda complexamente de acordo com as interações humanas e a construção semiótica possibilitada nestes encontros diz de um infindável campo de construção de sentidos, no qual nem sempre é possível estabelecer de uma única forma o que viria a ser a identidade de lugar.

Desta forma, este artigo pretende desenvolver considerações que fomentem eampliem as possibilidades de entendimento da categoria identidade de lugar. Tendo como método uma abordagem histórico-cultural de leitura da realidade. Inicialmente, o estudo se centrará numabreve definição denossa abordagem metodológica. Em prosseguimento, dissertaremos criticamente sobre 
o conceito de identidade de lugar proposto por Proshansky, Fabian e Kaminoff(1983), para, finalmente, apresentarmosnossas contribuições teóricas ao conceito.

\section{MÉTODO}

\section{Histórico-cultural}

A delimitação de nossa abordagem metodológica tangencia uma questão levantada por Vigotski na década de 1920. Naquela época, a Psicologia atravessava uma crise em suas bases, o que ameaçava inclusive seu estatuto de disciplina científica. Várias correntes disputavam pelo locus de representante verdadeira da Psicologia Científica. Neste ínterim, pesquisadores russos pós-revolução comunista iniciaram diversos trabalhos na tentativa, para muitos deles, de construir uma ciência psicológica de base marxista.

Um dos principais problemas estudados versava na tentativa de resolver a questão da relação entre subjetivo e objetivo em Psicologia. Isto é, na decifração da relação entre o mundo objetivo, concreto e mensurável no qual estavam inseridas as pessoas; e os sentimentos, sensações, pensamentos, tendências, consciência, personalidade e tudo aquilo que se acreditava interno ao sujeito, à sua mente.

Nesta perspectiva, Vigotski (2004) apontou que a relação entre "subjetivo" e "objetivo" fora palco de grandes distorções em Psicologia, havendo quem acreditasse numa impossibilidade de estudar cientificamente o que se denominou subjetivo como: emoções, pensamentos e sensações pelo fato de não serem "objetivos" ou "concretos", criando-se, assim, uma vertente empiricista focada na observação exclusiva de comportamentos externos e mensuráveis.

Por outro lado, havia as correntes que apontavam à busca de verdades reveladas a priori, por introspecção. Ou seja, concentravam-se em demonstrar a superficialidade dos estudos "comportamentalistas" ao modelo das ciências naturais, se apoiando na descrição dos processos internos por meio da introspecção como forma de conhecimento científico, o que equivaleria emparelhar a descrição subjetiva da sensação à construção de conhecimento objetivo-científico.
Assim, Vigotski (2004) afirmou que em ciência não caberia o estudo do que parece existir (subjetivo), isto indicaria o estudo do irreal; do qual a ciência não poderia se ocupar. Todavia, apontou uma saída à questão:

É impossível qualquer ciência só sobre o subjetivo, sobre o que parece, sobre fantasmas, sobre o que não existe. $\mathrm{O}$ que não existe não existe em absoluto, e não vale o 'meio não' e o 'meio sim'. [...] O irreal deve ser explicado como a não-coincidência, como a relação entre duas coisas reais; o subjetivo como conseqüência de dois processos objetivos. $\mathrm{O}$ subjetivo é o aparente, e por isso não existe (Vigotski, 2004, p. 386). ${ }^{1}$

Porém, embora a perspectiva vigotskiana pareça abandonar sua busca de uma Psicologia ao fazer tal declaração, na verdade mostra a chave necessária para a saída da crise. A questão é que ao se confundir o psíquico com o subjetivo, muitos teóricos marxistas de seu tempo inviabilizaram a pesquisa psicológica de fundamentação materialista; na inútil tentativa de explicar em termos "idealistas" o psiquismo identificado como algo não-material. Desta forma, para a perspectiva materialista defendida por Vigotski (2004), o psiquismo é uma construção objetiva, histórica, dialética e materialista, sendo passível de análise e explicação causal.

Ou seja, temos o psiquismo como uma construção objetiva pelo fato de ser construída a partir de outros eventos igualmente objetivos, sendo seu aspecto subjetivo somente aparência; histórica por estar inserida num contexto determinado pela cultura e ideologias próprias de uma sociedade e um tempo específico; dialética por se fundar na contradição imanente ao processo de construção da relação sujeito-objeto; e materialista por seu caráter concreto e de realidade.

Portanto, compreende-se o método histórico-cultural como um "caminho" de compreensão materialista histórico-dialética do sujeito que se funda nas interações sociais, estudado a partir do processo histórico-dialético de subjetivação-objetivação da realidade. Assim, esta fundação não se dá por um simples reagir a estímulos ambientais e sociais ou um ímpeto interno motivado por uma "consciência" a-histórica e imaterial. Mas

\footnotetext{
1 Grifos do autor e ortografia conforme edição consultada.
} 
sim, na atividade entendida como ação mediada por instrumentos e signos cultural e historicamente constituídos (Vigotski, 1998a). Por meio dos quais podemos "internalizar" ou se apropriar dos aspectos culturais constituídos historicamente, que são base de instrumentalização e regulação das funções psicológicas superiores que mediatizam a práxis transformadora da realidade.

Comisso, podemos afirmarqueo movimento de apropriação da realidade, ou melhor, da constituição histórica e cultural desta, mediado pelos signos e instrumentos, é basilar na concepção do sujeito em sua condição de agente de seu processo de subjetivação.

Dando seguimento, pensamos a apropriação em conformidade com Smolka (2000, p. 29), pois a concebemos "não estritamente ligada ao construto de internalização, mas relacionada principalmente ao problema da significação", ou seja,

Isso ancora nossa escolha por enfocar não as ações mediadas como tais (uma vez que assumimos que todas as ações humanas são, por sua natureza, inescapavelmente mediadas), mas por enfocar as significações da ação humana, os sentidos das práticas, considerando que todas as ações adquirem múltiplos significados, múltiplos sentidos, e tornam-se práticas significativas, dependendo das posições e dos modos de participação dos sujeitos nas relações (Smolka, 2000, p. 31, grifos da autora).

Logo, tal delimitação implica, dentro do nosso estudo, considerar a interação com os espaços não como uma simples ocupação corporal, mas como significação/apropriação ativa dos espaços físicos que passam a ter o caráter semiótico de lugar. Isto é, o espaço é transformado em lugar, em signo. E como tal assume um papel decisivo na construção subjetiva humana, uma vez que o signo, segundo Vigotski (1998a), funciona como mediador do comportamento humano e, por conseguinte, de sua estruturação subjetiva.

Não estamos negando a importância da ação humana mediada por instrumentos na ocupação e transformação dos espaços. Apenas estamos ressaltando que a "prática significativa", em estrita relação dialética com a ação concreta, produz sentidos e permite a apropriação subjetiva dos espaços físicos como signos histórica e culturalmente construídos. Isto é, lugar é signo.
Pensar a significação/apropriação dos espaços e lugares traz outro problema a ser delimitado neste momento metodológico. O caráter semiótico da relação pessoa/ambiente abre muitas possibilidades de construção de sentidos. Ao considerar este movimento como sendo instável e mutante, pode-se cair numa infindável gama de orientações teórico-metodológicas. Todavia, se ressalta que o posicionamento adotado neste trabalho tem proximidade com os construtos teóricos de Mikhail Bakhtin (1986).

Interessa entender com Bakhtin (1986) que o signo, além da função mediadora, identificada também no pensamento de Vigotski, se reveste por seu caráter histórico e cultural com o tecido ideológico. O signo se constroi na condição de signo ideológico, portanto nunca neutro eindividual.

Cada um dos demais sistemas de signos é específico de algum campo particular da criação ideológica. Cada domínio possui seu próprio materialideológico e formula signos e símbolos que lhe são específicos e que não são aplicáveis a outros domínios. O signo, então, é criado por uma função ideológica precisa e permanece inseparável dela (Bakhtin, 1986, p. 36-37).

Ou seja, articular teoricamente os sistemas de signos como resultantes de algum tipo de criação ideológica, indica, neste estudo, a assunção de que os lugares são produções ideológicas. Pois, conforme foi declarado anteriormente, se deve entender a relação de apropriação/significação dos espaços e lugares não simplesmente como uma questão de ocupação física, mas sob o foco da produção de signos históricos e culturais. Logo, acompanhando o raciocínio de Bakhtin (1986), pode-se afirmar que os lugares, espaços e até mesmo os não-lugares (Augé, 2007) são todos construídos ideologicamente e respondem, consequentemente, a interesses sociais dos grupos humanos que sustentam sua construção, manutenção, reprodução e transformação.

Desta forma, não seguimos uma vertente naturalista por compreendermos que esta posição admite os ambientes apenas em seus aspectos físicos, aos quais o sujeito deve se adaptar. Outra questão é que nesse caminho a afetividade e a atividade semiótica fatalmente seriam conceituadas uma em termos de afetação do organismo em resposta ao ambiente e a outra como mera ferramenta social necessária à 
adaptação e interação intersubjetiva. Assim, em tal vertente não teríamos como construir uma perspectiva de ação ético-política.

O caminhoidealista também reduziria nosso conceito a um fenômeno imaterial e a-histórico. Onde a questão do ambiente ficaria em segundo plano, pois, percorrendo a lógica deste sistema, constatamos que o sujeito possui potencialidades de caráter essencializadas e universais. Isto é, independentemente da vinculação histórico-cultural, o sujeito desenvolveria sua identidade na condição de impulso interno ao crescimento.

Logo, identificamos que o estudo do conceito de identidade de lugar, numa perspectiva histórico-cultural, deve necessariamente compreender a relação do ser humano com os espaços e lugares pelo caminho da atividade semiótica afetivo-política ${ }^{2}$ (Sawaia, 2000, 2006) de significação destes. Considerando também que esta atividade não diz respeito somente à mera construção de significados e sentidos referentes aos lugares, antes afirmamos que ela constitui o mecanismo de significação do próprio sujeito em interação com a alteridade - pessoas e lugares.

Ou seja, o sujeito, ao constituir significado e sentido aos espaços físicos, além de construir lugares semióticos, reconhece a si mesmo e a alteridade ora como individualidade que se apresenta "reificada", ora como negação de si como objeto de si mesmo e afirmação de si em processo. $\mathrm{O}$ que implica, na concepção de Ciampa (1995), se compreender em "metamorfose"; isto é, como sujeito em ação afetivo-política constante de apropriação/ significação de si, do outro e dos lugares.

Assim, a partir da perspectiva históricocultural, reforçamos o conceito de identidade proposto por Ciampa (1995). Para o autor, a identidade deve ser entendida como construção histórica, social e dialética, sendo por isso impossível concebê-la estática. Identidade, nesta perspectiva, assume uma postura de "metamorfose", que implica em constante transformação e contradição de si mesma. Todavia esclarecemos que esse autor não se propõe em criar uma terminologia específica para a interação da identidade com o processo de significação/apropriação dos lugares.
Desta forma, ao abordar a questão de uma categoria de identidade de lugar na perspectiva histórico-cultural, revelamos nosso interesse afetivo ético-político de lidar com as representações e significações do ambiente, pois pensamos que toda identidade de lugar se constroi numa relação afetiva e política de significação/ apropriação do espaço.

Portanto, conforme afirmamos anteriormente, a interação identidade e lugares se dá pelo viés de uma afetividade ético-política, proposta por Sawaia $(2000,2006)$, na qual entendemos que o ser humano se engaja afetiva ética-politicamente na construção de sua identidade, firmando laços com os lugares significativos de sua história. Abrindo, então, um campo de discussão crítica de transformação das "estruturas cristalizadas" e "reificadas" que formam a concepção alienada de lugar, por meio da qual a pessoa reproduz e "naturaliza" ideologias e discursos de exclusão.

Interessa explicitar que a categoria afetividade utilizada neste estudo não reflete uma entidade a priori, que existe em si e por si, como encontramos em pesquisas de cunho psicologizante. Nessa perspectiva, o indivíduo é supervalorizado e responsabilizado por seus sofrimentos e padecimentos, bem como enaltecido com suas conquistas pessoais, que são vistas como frutos legítimos de seus esforços particulares. Não aderimos, por sua vez, uma postura sociologizante, na qual os afetos não entram, ou são negligenciados, no cômputo das pesquisas que se desenvolvem no campo social.

A categoria afetividade é afirmada neste ensaio seguindo os estudos de Sawaia $(2000,2006)$, que a compreende "como dimensão fundamental da ação transformadora" (Sawaia, 2000, p. 6). Não é considerada simplesmente uma força sem regras, que por causa de seu perigo necessita de controle. $\mathrm{E}$, antes de tudo, a união inextricável de afeto e política, reforçando aquilo que segundo a autora define a categoria afetividade ético-política, pois:

unir afeto à ética é explicitar a preocupação com "a virtude como dimensão da verdade", e uni-lo à política, é salientar a preocupação com a justiça e o poder. Porém, é preciso

\footnotetext{
2 A autora relaciona o conceito de afetividade a um posicionamento político e ético que proporciona disposições a uma ação transformadora do indivíduo na sociedade. Esta interação entre afeto e ética deve ser entendida como ontológica e base de todas as ações humanas.
} 
esclarecer que esta junção não pode recorrer a colas gramaticais como o hífen, para unir artificialmente instâncias distintas. Esta junção deve ser ontológica, de forma a revolucionar as concepções cindidas e as que colocam a explicação do sujeito a reboque da sociedade, e assim acenar com a possibilidade de se tomar decisões éticas sem um código rígido ou um juiz implacável (sawaia, 2000, p. 14).

Sawaia encontra essa condição ontológica da afetividade ético-política no filósofo Spinoza (1979) que em sua obra Ética argumenta que a vida ética começa no interior das paixões. Para o autor, não a razão pura ou prática, mas as paixões seriam as molas propulsoras da atividade ética e política. Principalmente, quando estas se encaminham não ao bem individual e narcisista, mas, ao contrário disso, à satisfação e alegria coletiva. O que geraria potência de ação (conatus) e diminuição da potência de padecimento. A primeira ligada ao "corpo e alma livres" e a segunda às afecções do "corpo e da alma escravos".

Logo, Sawaia afirma que para Spinoza "o sujeito é ético porque age em nome da liberdade e não da recompensa. Aos escravos, e não ao homem livre, se dá recompensa pela boa conduta" (2000, p. 29). Com isso:

a força coletiva que pode se transformar no sujeito político, herói da inovação da vida, está no desejo de ser comandado apenas por si e na compreensão que o sumo bem (amor intelectual) é o outro homem, bem como no reconhecimento que este desejo, quando coletivo é mais poderoso do que o individual (Sawaia, 2000, p. 29-30). ${ }^{3}$

Ou seja, nosso conceito de identidade de lugar se compromete, de forma afetiva ético-política, com a transformação crítica que "desnaturaliza" a legitimação e reprodução de ideologias e estigmas, os quais fortalecem a potência de padecimento e negam as possibilidades do devir, ou seja, o movimento dialético próprio da relação históricocultural do sujeito com os lugares.

Contudo, afirmamos que mesmo nessa postura crítica não abandonamos aquilo que nos foi alertado por Bakhtin (1986), a saber, que tal movimento, em virtude de seu caráter semiótico, não anula uma nova construção, igualmente social e, por conseguinte, ideológica. O que não implica dizer que esse novo construto, por ser também ideológico, deva necessariamente reproduzir os mesmos valores que outrora foram denunciados.

\section{Identidade de lugar: caminho em construção}

Proshansky et al. (1983) conceituaram identidade de lugar como uma subestrutura da identidade pessoal constituída por cognições sobre o mundo físico em que a individualidade habita. Tais cognições representam memórias, ideias, valores, sentimentos, atitudes, significados e concepções de comportamento e experiência, os quais estão relacionados com a variedade e complexidade dos lugares físicos que definem a existência cotidiana de cada ser humano. Nesta perspectiva, a identidade de lugar deve ser compreendida como uma construção pessoal, onde as experiências diretas com o ambiente físico a modificam. Por sua vez, essas experiências são transformadas pelos processos cognitivos.

Embora este conceito não se prenda à concepção da identidade de lugar como algo estático - permitindo até mesmo uma possibilidade de articulá-la com uma proposta interacionista -, constatamos facilmente que sua ideia central é da identidade como construção pessoal, própria do resultado da interação funcional do sujeito com o ambiente. Neste caso, temos aqui um conceito que na verdade se assemelha bastante com a proposta do interacionismo simbólico de George Mead (1970), importante pesquisador do Behaviorismo Social e seguidor do pragmatismo de Dewey.

Para Mead (1970), as interações sociais e o uso da linguagem constroem a mente e o self; o que permite ao indivíduo biológico ter uma ação reflexiva sobre si mesmo, pensar-se como objeto, podendo neste ato controlar suas ações e a dos outros através dos símbolos socialmente construídos. Em sua teoria, a linguagem é explicada como uma ferramenta construída a partir da necessidade de interação dos indivíduos biológicos. Neste contexto, podemos afirmar que sua proposta

\footnotetext{
Ortografia conforme texto original.
} 
segue uma vertente na qual não há distinção entre signos e instrumentos, como ocorre na teoria de Vigotski. Desta forma, temos o signo ou símbolo como um instrumento de mediação das relações do organismo, mas a diferença fundamental da perspectiva vigotskiana reside na utilização do símbolo apenas como um instrumento igual a todos os outros. Tendo também sua condição ideológica não considerada como algo fundamental e imprescindível na constituição deste signo.

Ou seja, para o interacionismo simbólico, a utilização da linguagem é comparável ao uso de uma ferramenta que facilita as atividades humanas. Divergindo qualitativamente da concepção de Vigotski (1998a, 1998b) na qual, além do caráter de mediação, esta assume papel decisivo na organização das funções psicológicas superiores e na compreensão da construção materialista e social do psiquismo. Além disso, há divergência também do caráter ideológico, histórico e contextualizado da linguagem, de acordo com o trabalho de Bakhtin (1986).

Outra questão relativa à teoria de Mead (1970) é a compreensão das relações sociais por um viés darwinista e pragmático. Segundo este autor, o indivíduo biológico interage com os outros indivíduos na tentativa de se adaptar ao ambiente. Seguindo este raciocínio, temos que alguns indivíduos são mais aptos a adaptações que outros, por possuírem melhores mecanismos que garantam sua sobrevivência.

Tal leitura refuta nosso posicionamento de pensar o sujeito histórica e culturalmente contextualizado, pois, ao defender a tese do indivíduo biológico responsável por sua própria adaptação ao ambiente refletindo posturas liberais próprias do pensamento pragmático, George Mead (1970) nega a possibilidade da organização solidária, enquanto manifestação da afetividade ético-política. Admitindo-a apenas por interesses exclusivamente racionais e evolucionários, onde a sociedade existe apenas como reflexo da evolução do homem no enfrentamento da natureza em direção a uma sociedade universal.

No mesmo caminho sócio-fisiológico que o indivíduo humano torna-se autoconsciente. Torna-se também consciente dos outros indivíduos; e sua dupla tomada de consciência, de si mesmo e dos outros, é igualmente importante para seu próprio desenvolvimento e para o desenvolvimento da sociedade organizada ou do grupo social ao qual pertence (Mead, 1970, p. 253). ${ }^{4}$

Deste modo, identificamos que a proposta de Mead (1970) se afasta de nossos postulados teóricos, metodológicos e éticos. Pois este assume uma postura que privilegia a racionalidade e o evolucionismo social, considerando a sociedade, como um organismo, num contínuo progresso evolucionário em direção a sua "mais avançada forma de organização": a sociedade democrática, de valores cristãos e de economia liberal.

Assim, articulando o conceito de identidade de lugar de Proshansky et al. (1983) com o interacionismo simbólico de Mead (1970), temos que os referidos autores se aproximam bastante epistemologicamente. Em ambas as concepções encontra-se um sujeito que, embora em interação, não é visto como um agente considerado ontologicamente em sua condição afetiva éticopolítico, antes é reduzido apenas a sua condição de ator sócio-biológico em interação com o ambiente.

E esta é a questão que apontamos: não negamos a condição biológica do ser humano, pois estaríamos renunciando nosso postulado materialista e objetivo. Contudo, a simples redução da condição humana a esta característica rejeita sua capacidade imanente de se comprometer de forma afetiva ético-política, no caso deste estudo, com a ressignificação das relações de identificação com os espaços e lugares, nos quais o ser humano está inserido histórica e culturalmente.

Reconhecemos a importância dos estudos de Proshansky et al. (1983) e de suas ideias sobre identidade de lugar. Todavia, situamo-nos em terrenos epistemológicos diferenciados e, na maioria das vezes, antagônicos. O que implica considerar que a justaposição ou emendas teóricas entre nossos postulados causaria mais inconsistências do que conceituações sólidas.

\section{CONSIDERAÇÕES FINAIS}

Finalizamos este artigo mostrando alguns vínculos inextricáveis mediante os quais compreendemos as categorias espaço, lugar e nãolugar, a saber: interação dialética de significação e

\footnotetext{
4 Tradução livre do original em inglês.
} 
ressignificação; proximidade e afastamento; segurança e liberdade; reconhecimento e estranhamento. Facilita-nos construir uma perspectiva na qual o espaço e o lugar estão marcados por sua transitoriedade e mobilidade. Não há o lugar fixo e imutável, facilmente reconhecível por todos uniformemente, porque "cristalizar essa identidade é como retratar a cidade sem oxigênio, habitada por seres sem vida", argumenta Sawaia (1995, p. 21) e prossegue a autora dizendo que "perguntar pela identidade de uma cidade não é buscar a unidimensionalidade, mas olhar as ambigüidades, ${ }^{5}$ as negociações e os confrontos em suas diferentes mediações."

Daí o não-lugar (Augé, 2007) apresentarse como produtor de identidades cristalizadas a serem consumidas solitariamente, pois o amortecimento do calor das negociações e confrontos gera controle a priori das regras, valores, afetos e condutas a serem exercidos dentro deste locus. O que não impede a superação destes limites em eventuais rupturas com a ordem estabelecida. Principalmente, a partir da intervenção afetiva éticopolítica das pessoas na relação com o ambiente.

Desse modo, as constantes intervenções dos sujeitos no ambiente " ora significando lugares, ora deslocando-se pelo espaço (lugar praticado, conforme Augé, 2007), ora consumindo os nãolugares "implicam num constante movimento onde a ação ético-política dos sujeitos torna-se de grande importância para que haja uma construção de identidades que possam ser postas e repostas no processo de significação/apropriação do ambiente.

Assim, pensamos que a construção histórico-cultural e afetivo-política de uma identidade de lugar nunca pode deixar de considerar a perspectiva da mobilidade dos sujeitos. E nesse sentido, entendemos que o aumento do fluxo migratório e os deslocamentos produzem encontros e desencontros entre diversas culturas, provocando a indefinição daquilo que chamamos de "meu lugar". Mesmo com tudo isto, não há como subtrair o aspecto de que estas pessoas em "trânsito" constante pelos espaços, lugares e não-lugares acabam sempre criando referenciais simbólicos, afetivos, estéticos e éticos que, antes de serem simples referências espaciais, são representações de si mesmas.

Para além da reificação monossêmica do ambiente, restam sempre a diversidade de ações e as possibilidades contraditórias da existência semântica numa mesma realidade. Por isso, concordamos com Sawaia (1995, p. 23) quando aponta a multidimensionalidade dos espaços urbanos e nega o paradigma do "uno"; notadamente nestas palavras:

[...] da identidade igual a si mesma, destacando o processo de diluição entre si de contrários, como segregação e resistência, intimidade e impessoalidade. Um mesmo espaço contém o "estar junto" eo "estardiscriminado", a exclusão e a inclusão, a autonomia e a heteronomia.

Assim, destacamos que o caminho que leva a se pensar o lugar a partir da unidimensionalidade traz consigo uma perspectiva "tirânica" (Sawaia, 1995). A "maquiagem" da realidade, difundida em discursos que pregam a unidade e "inclusão solidária" retroalimentam dialeticamente, na verdade, o mecanismo de exclusão; impedindo o que Spinoza (1979) chama a "potência de ação" e embotam aquilo a que Sawaia $(2000,2006)$ se refere como a afetividade ético-política. Tal maquiagem gera assim uma perspectiva alienada de relacionamento e uso dos espaços, lugares e não-lugares como objetos de consumo, mercadorias com diversos rótulos: "área nobre", "favela", "zona de risco", "refúgio", "shopping center", entre outros.

Portanto, ressaltamos que, no atual contexto, marcado por constantes transformações identitárias, a ação afetiva, ética e política dos sujeitos na apropriação/significação dos lugares passa pelo que Sawaia $(2000,2006)$ denominou de "bons encontros". O que não significa todo mundo ser bonzinho e politicamente correto ou tentar construir por unanimidade uma forma de corrigir os defeitos e as feiúras dos lugares e das relações lá existentes. Porque a questão, nos diz a autora, "não é garantir a não-segregação, pois jamais se atinge o ponto ótimo de participação plena, mas potencializar a capacidade de enfrentar os novos e criativos processos de exclusão que se constroem incessantemente" (Sawaia, 1995, p. 24).

Ou seja, trata-se da potencialização do locus onde o discurso afetivo ético-político possa tomar corpo e construir mecanismos de enfrentamento dos processos de exclusão e alienação nas relações de apropriação/significação dos lugares. E, nesse sentido, a expressão "bons encontros"

\footnotetext{
Ortografia em conformidade com o texto original.
} 
significa promover o diálogo e a vivência com a alteridade. Portanto, a afirmação da identidade de lugar torna-se um processo dialógico-afetivo contínuo e multidimensional, onde o sujeito da ação - afetiva, ética e política - interage com a alteridade e se permite negociar novas possibilidades de existência, na qual a participação e o sentimento de pertença vão além da ideologia que mascara a dialética exclusão/inclusão (Sawaia, 2006).

\section{AGRADECIMENTOS}

Agradecemos à Fundação Cearense de Apoio ao Desenvolvimento Científico e Tecnológico (FUNCAP) por concessão da bolsa de mestrado, sem a qual não seria possível concretizar-se os estudos necessários à produção deste artigo.

\section{REFERÊNCIAS}

Augé, M. (2007). Não-lugares: Introdução a uma antropologia da supermodernidade (6a ed.). São Paulo: Papirus.

Bakhtin, M. (1986). Marxismo e filosofia da linguagem (3a ed.). São Paulo: Hucitec.

Ciampa, A. C. (1995). Identidade. In S. T. M. lane, \& W. codo, (Org.). Psicologia social: O homem em movimento. São Paulo: Editora Brasiliense, 1995.

Fourez, G. (1995). A construção das ciências: Introdução à filosofia e à ética das ciências. São Paulo: Editora da Universidade Estadual Paulista.

INSTITUTO BRASILEIRO DE GEOGRAFIA E ESTATÍSTICA - IBGE. (2003). Censo Demográfico 2000: Migração e deslocamento. Rio de Janeiro: IBGE.

Mead, G. H. (1970). Mind, self and society: From the standpoint of a social behaviorist. Chicago: The University of Chicago Press.

Pol, E., \& Valera, S. (1999). Symbolisme de l'espace public et identitée sociale. Villes en Paralèlle, 28(29), 13-33.
Proshansky, H. M., Fabian, A. K., \& Kaminoff, R. (1983). Place-identity: physical world socialization of the self. Journal of Environmental Psychology, 3(1), 57-83.

Sawaia, B. B. (1995). O calor do lugar: Segregação urbana e identidade. São Paulo em Perspectiva, 9(2), 20-24.

Sawaia, B. B. (2000). Por que investigo afetividade?. PUC-SP.

Sawaia, B. B. (2006). O sofrimento ético-político como categoria de análise da dialética exclusão/ inclusão. In: B. B. Sawaia. (Org.). As artimanhas da exclusão: Análise psicossocial e ética da desigualdade social (6a ed.). São Paulo: Vozes.

Smolka, A. L. B. (2000). O (im)próprio e o (im)pertinente na apropriação das práticas sociais. Cad. Cedes, 20(50), 26-40.

Spinoza, B. (1979). Ética. (Os pensadores. 2a ed.). São Paulo: Abril Cultural.

Tuan, Y. F. (1983). Espaço e lugar: A perspectiva da experiência. São Paulo: Difel.

Vigotski, L. S. (1998a). A formação social da mente (6a ed.). São Paulo: Martins Fontes.

Vigotski, L. S. (1998b). Pensamento e linguagem (2a ed.). São Paulo: Martins Fontes.

Vigotski, L. S. (2004). Teoria e método em psicologia (3a ed.). São Paulo: Martins Fontes.

Recebido: 15/05/2009

Received: 05/15/2009

Aprovado: 15/06/2009

Approved: 06/15/2009

Revisado: 11/12/2009

Reviewed: 12/11/2009 